\title{
When mothers talk about their past habits: A case study of stunting in Kendary City, Indonesia
}

\author{
Lisnawaty*1 $^{* 1}$ Meynanda ${ }^{2}$, Fithria $^{3}$, Irma Yunawati ${ }^{4}$, Febriana Muchtar ${ }^{5}$ \\ ${ }^{1,2,3,4,5}$ Bagian Gizi, Univeristas Halu Oleo, Kendari
}

DOI: 10.24252 /al-sihah.v12i2.15558

Received: 28 August 2020 / In Reviewed: 30 September 2020/ Accepted: 15 September 2020 / Available online: 19 September 2020

(C) The Authors 2020. This is an open access article under the CC BY-NC-SA 4.0 license

\begin{abstract}
Stunting can be a nutritional problem that will adversely affect the optimal development process of children according to their genetic potential. Stunting can hinder the process of growth and development in under-fives. This study aimed to determine the causes of stunting in under-fives in the Abeli sub-district, Kendari City. The method of study was descriptive qualitative by a case study design. Data obtained through in-depth interviews of 4 (four) key informants and 5 (five) ordinary informants. Based on the results of the study, it was known that the incidence of stunting in the Abeli sub-district was caused by low birth weight, exclusive breastfeeding, and complementary feeding. It was based on the results of interviews, of four under-fives were stunting, there were three under-fives had a birth weight $<2500$ grams. The reason was because of inadequate breast milk production and a lack of family support for mothers to provide exclusive breastfeeding to under-fives. The reason was that the mother did not carry out routine pregnancy checks so that the condition of the fetus was poorly monitored. Besides, all under-fives who were stunting did not receive exclusive breastfeeding. In giving complementary feeding, the mothers gave complementary feeding to under-fives too early. Besides, a portion of the meal did not meet the needs of under-fives and less varied food.
\end{abstract}

Keywords:, , complementary feeding; exclusive breastfeeding; low birth weight

\begin{abstract}
ABSTRAK
Stunting dapat menjadi masalah gizi yang akan berdampak buruk terhadap proses tumbuh kembang anak yang optimal sesuai potensi genetiknya. Stunting dapat menghambat proses tumbuh kembang pada balita. Tujuan penelitian adalah untuk mengetahui penyebab kejadian stunting pada anak balita di Kecamatan Abeli Kota Kendari. Metode penelitian adalah deskriptif kualitatif dengan desain studi kasus. Data diperoleh melalui wawancara mendalam kepada 4 informan kunci, dan 5 informan biasa. Berdasarkan hasil penelitian diketahui bahwa kejadian stunting di kecamatan Abeli disebabkan oleh BBLR, pemberian ASI eksklusif dan pemberian MP-ASI. Hal ini berdasarkan hasil wawancara yang dilakukan, di mana empat balita yang mengalami stunting, terdapat tiga balita yang memiliki berat badan lahir $>2500$ gr. Seluruh anak balita yang mengalami stunting tidak mendapatkan ASI eksklusif, alasannya karena produksi ASI yang tidak adekuat dan kurangnya dukungan keluarga kepada ibu untuk memberikan ASI eksklusif kepada balita. Selain itu, penyebabnya dikarenakan ibu tidak melakukan pemeriksaan kehamilan secara rutin sehingga kondisi janin kurang terpantau. Dalam pemberian MP ASI, ibu terlalu dini memberikan MP-ASI kepada balita, selain itu porsi makan yang tidak sesuai kebutuhan balita serta makanan yang kurang bervariasi.
\end{abstract}

Kata Kunci : bblr; pemberian asi eksklusif; pemberian mp-asi

*Alamat Korespondensi:

Jl. Sakura No. 8A, Kel. Anduonohu, Kec. Poasia, Kendari, 92392

Email: lisnawaty@uho.ac.id
ISSN-P : 2086-2040

ISSN-E : 2548-5334

Volume 12, Nomor 2, Juli-Desember 2020 


\section{PENDAHULUAN}

Kekurangan gizi menjadi salah satu masalah utama morbiditas dan mortalitas pada balita di negara berkembang (Black et al., 2013). Temuan beberapa penelitian menunjukkan bahwa gizi buruk selama masa kanak-kanak merupakan salah satu kondisi terpenting yang menghambat perkembangan fisik dan mental anak yang mana akhirnya menyebabkan terjadinya malnutrisi antar generasi (Rasheed \& Woods, 2013) (Huang et al., 2013). Akibatnya, pengaruh malnutrisi pada anak di bawah lima tahun bersifat permanen dan berlanjut hingga dewasa (Ampaabeng \& Tan, 2013)

Diperkirakan sekitar 178 juta-195 juta anak-anak di seluruh dunia mengalami kekurangan gizi, dan pada saat tertentu, 20 juta menderita kekurangan gizi buruk. Diperkirakan 230 juta anak balita diyakini mengalami kekurangan gizi kronis di negara berkembang dan kekurangan gizi pada balita merupakan salah satu masalah kesehatan masyarakat yang paling penting di negara berkembang khususnya Indonesia. (World Health Organization, 2013)

Di Indonesia, malnutrisi pada anakanak merupakan hasil dari banyak faktor yang saling terkait termasuk lingkungan, ekonomi, pendidikan, dan budaya serta pelayanan kesehatan (De Silva \& Sumarto, 2018). Di antara yang memiliki efek langsung kejadian malnutrisi adalah kondisi ekonomi pada masyarakat. Dengan demikian, tingkat gizi anak dapat menunjukkan bagaimana perkembangan sosial ekonomi suatu masyarakat (Husseini et al., 2018).

Pemberian gizi yang efektif adalah salah satu penentu status kesehatan masyarakat pada negara mana pun termasuk Indonesia (Mahmudioni et al., 2016). Namun, malnutrisi tetap menjadi ancaman terbesar bagi hampir semua wilayah di Indonesia. Stunting (tinggi badan rendah untuk usia) adalah hambatan kronis potensi pertumbuhan anak yang disebabkan karena kekurangan asupan gizi. Secara khusus, ini mengacu pada anak-anak dari usia 0-59 bulan yang panjang atau tinggi tubuhnya berada minus 2 dari standar Multicentre Growth Reference Study dari Organisasi Kesehatan Dunia (Akombi et al., 2017).

Faktor penyebab stunting pada anak balita bervariasi menurut usia dan secara ekologis terkait satu sama lain (Goudet et al., 2017). Diantaranya, faktor lingkungan dalam rumah tangga yaitu ketahanan pangan rumah tangga serta sanitasi dan personal hygiene memegang peranan penting dalam pencegahan stunting dalam jangka panjang (Abdurrahman et al., 2016) (Altmann et al., 2018). Lingkungan rumah tangga yang berkaitan dengan gizi anak terdiri dari persepsi pengasuh terhadap rawan pangan (Abu Bakar et al., 2011), kesehatan anak 
dan pemilihan pangan (Coghlan \& Bhagwat, 2019), dan status sosial ekonomi rumah tangga (Kien et al., 2016). Faktor lingkungan intra rumah tangga ini berkontribusi pada pengabaian kebutuhan anak, terutama status gizi sejak lahir hingga prasekolah. Selain itu, lingkungan intra rumah tangga dipengaruhi oleh faktor lingkungan, budaya, dan sejarah di mana ibu bertempat tinggal (Donini et al., 2015).

Beberapa anak balita di Indonesia telah menunjukkan tanda-tanda gagal tumbuh (Rohmah et al., 2018), rambut kekurangan Zinc (Oktiva \& Adriani, 2017), diare serta kondisi higienis yang buruk (Desyanti \& Nindya, 2017). Anak-anak yang mengalami stunting cenderung mendapatkan risiko kematian dini di kemudian hari karena organ vital yang tidak pernah berkembang sepenuhnya selama masa pertumbuhan (Myatt et al., 2019). Anak-anak yang kekurangan gizi akan lebih mudah resisten terhadap infeksi serta lebih berpotensi meninggal karena penyakit seperti infeksi saluran pernapasan akut dan diare (Kinyoki et al., 2017).

Saat ini terdapat 144 juta anak mengalami stunting di seluruh dunia dan Asia Tenggara menjadi wilayah yang terbanyak dengan jumlah kasus stunting sebanyak 55.9 juta anak (World Health Organization et al., 2020). Prevalensi kejadian stunting pada anak di Indonesia tetap tinggi selama
10 tahun terakhir, yaitu sekitar 37\% dari jumlah anak di Indonesia (Beal et al., 2018). Di Provinsi Sulawesi Tenggara tahun 2016 prevalensi pendek anak balita yaitu $20.6 \%$, dan sangat pendek $8.9 \%$. Kemudian pada tahun 2017 mengalami peningkatan, prevalensi pendek anak balita $21.2 \%$ dan sangat pendek yaitu $15.2 \%$. Kemudian pada tahun 2018 prevalensi balita yang mengalami stunting sebanyak 34.2\% (Dinas Kesehatan Prov.Sulawesi Tenggara, 2019).

Kendari merupakan ibu kota yang ada di Provinsi Sulawesi Tenggara. Data dari Dinas Kesehatan Kota Kendari menunjukkan prevalensi stunting pada tahun 2016 yaitu sebesar $22.5 \%$. Kemudian pada tahun 2017 prevalensi stunting mengalami peningkatan menjadi $37.1 \%$. Untuk di Kecamatan Abeli Kota Kendari, terdapat 4 balita yang mengalami stunting pada bulan Januari-Oktober tahun 2018 (Dinas Kesehatan Kota Kendari, 2019). Penelitian ini bertujuan untuk mengetahui penyebab kejadian stunting pada ke 4 balita tersebut di Kota Kendari, Sulawesi Tenggara.

\section{METODE PENELITIAN}

Jenis Penelitian ini adalah deskriptif kualitatif dengan desain studi kasus. Jumlah informan sebanyak 4 orang ibu balita sebagai informan kunci, 3 orang keluarga informan kunci yang dijadikan 
sebagai informan biasa, dan 2 orang petugas kesehatan yang terdiri dari kader posyandu dan tenaga pelaksana gizi. Penentuan informan pada penelitian ini dilakukan dengan teknik purposive sampling. Penelitian ini dilaksanakan di Kecamatan Abeli Kota Kendari selama bulan JuliAgustus 2019. Jenis data yang digunakan dalam penelitian ini adalah data sekunder yang diperoleh dari literatur buku, jurnal, dan laporan kesehatan institusi kesehatan serta data primer dari hasil wawancara mendalam (in dept interview). Hasil wawancara kemudian disajikan dalam bentuk narasi disertai penjelasan.

\section{HASIL PENELITIAN}

Penelitian ini mengkaji tentang kejadian stunting di kecamatan Abeli kota Kendari dengan menelusuri tiga faktor penyebab kejadian stunting yakni, Berat Badan Lahir Rendah (BBLR), pemberian ASI eksklusif dan pemberian MP-ASI.

Dari hasil wawancara dengan informan kunci (ibu balita) didapatkan bahwa dari empat Balita yang mengalami stunting, terdapat tiga Balita yang lahir dengan kondisi BBLR. Di mana berat badan ketiga balita tersebut saat lahir <2500gr. Ketika lahir, 3 anak mengalami BBLR sedangkan 1 lainnya mempunyai berat badan lahir 2700gr. Berikut kutipan wawancara dari informan:
“... Anak saya waktu lahir itu beratnya 2,400 gr...” (Ny. Nt).

“... pada saat saya melahirkan berat anak saya 2,700 gr ...” (Ny. DN).

Hasil wawancara juga didukung oleh informan biasa selaku petugas pelaksana gizi di Puskesmas Abeli yang menyatakan bahwa BBLR merupakan faktor utama terjadinya stunting wilayah kerja Puskesmas Abeli. Berikut kutipan wawancaranya:

“... yang kami dapati di lapangan balita yang mengalami stunting, saat lahir memang BBLR. Jadi dapat dikatakan bahwa BBLR merupakan faktor penyebab terjadinya stunting di wilayah ini ..." (Nn. Ri).

Dari hasil penelitian diketahui bahwa BBLR memiliki risiko terhadap kejadian stunting di Kecamatan Abeli Kota Kendari.

Dari hasil wawancara diperoleh hasil yang menyatakan bahwa ke empat ibu balita yang mengalami stunting tidak memberikan ASI ekslusif kepada anaknya. Dua informan menyatakan tidak memberikan ASI ekslusif kepada anaknya dengan alasan bahwa ASI yang keluar tidak banyak, maka untuk mencukupi kebutuhan anaknya diberikan susu formula. Informan lainnya mengatakan bahwa alasan tidak memberikan ASI kepada balita karena ibu sedang menderita penyakit infeksi menular sehingga ibu takut anaknya akan tertular penyakit. Sedangkan informan lainnya menyatakan memberikan ASI kepada anaknya namun tidak ekslusif karena berat badan anaknya kurang, sehingga anak- 
nya diberikan susu formula untuk membantu menambah berat badan anak. Berikut kutipan wawancaranya:

“... Saya tidak memberikan ASI sejak anak saya lahir. Saya berikan susu formula karena takutnya dia tertular penyakit saya, mertua dan suami saya melarang saya untuk memberikan ASI katanya jangan sampai anak saya ikut tertular penyakit ...".(Ny. Rt).

“... saat lahir saya memberikan ASI kepada anak saya. Tetapi pada usia 2 bulan mulai dibantu dengan susu formula. Biasa 2 botol susu setiap harinya. Soalnya anak saya itu badanya kurus jadi saya memberikan susu formula agar berat badannya naik ..."(Ny. Nf).

“... setelah melahirkan ASI saya tidak keluar. Sejak lahir anak saya langsung diberikan susu formula. ASI saya mulai keluar nanti setelah satu minggu setelah melahirkan. Jadi terkadang saya berikan susu formula, kadang juga saya beri ASI ... "(Ny. Dn).

“... sejak lahir anak saya sudah saya berikan ASI, tapi umur 5 bulan saya sudah berikan susu formula, soalnya ASI saya yang keluar sudah mulai sedikit. Setiap hari anak saya itu minum dua sampai tiga botol susu botol susu, tapi terkadang saya juga masih memberikan ASI"'(Ny. Nt).

Pernyataan dari informan kunci didukung dengan pernayataan dari informan biasa yang merupakan keluarga yang tinggal serumah dengan informan kunci, yang menyatakan bahwa benar adanya anak diberikan susu formula oleh ibunya. Berikut kutipan wawancaranya :

“... sejak lahir anaknya sudah dikasih susu formula, karena air susunya tidak keluar sama sekali ..."(Ny. Rn).

“... anaknya dari lahir itu sudah dikasih susu formula, karena ibunya menderita TBC, kita sebagai keluarganya melarang untuk memberikan ASI kepada anaknya soalnya takut ketularan penyakitnya ..."(Ny. Dw).

Hal ini di perkuat dengan pernyataan dari informan biasa yang merupakan petugas poli gizi di Puskesmas Abeli. Di mana cakupan pemberian ASI Ekskusif di wilayah kerja puskesmas Abeli masih tergolong rendah. Berikut kutipan wawancaranya:

“... cakupan pemberian ASI ekslusif diwilayah kerja Puskesmas Abeli masih cukup rendah, salah satu penyebab rendahnya pemberian cakupan pemberian ASI Ekslusif yaitu karena masih rendahnya pemahaman ibu mengenai konsep pemberian ASI ekslusif kepada anaknya. Selain itu kurangnya dukungan dari anggota keluarga agar ibu memberikan susu formula kepada anaknya ..."(Ny. Ri).

Dalam hal frekuensi pemberian ASI, dua informan menyatakan bahwa memberikan ASI kepada anaknya 2 sampai 3 kali dalam sehari, kemudian 1 informan mengatakan memberikan ASI kepada sebanyak 4 kali dalam sehari, sedangkan 1 informan tidak memberikan ASI samasekali kepada anaknya. Berikut kutipan wawancaranya :
“... dalam sehari, tidak menentu saya memberikan ASI, kira-kira 3 kali dalam sehari ..."(Ny. Nt).
“... awalnya saya memberikan ASI 4 
kali dalam sehari, tapi kalau anak saya sudah minum susu formula, saya kasih ASI hanya 1 kali dalam sehari ..."(Ny. $\mathrm{Nf}$ ).

“... Kadang dua kali, kadang juga tiga kali sehari, tergantung kondisi, soalnya kadang ASI saya yang keluar kadang banyak kadang sedikit, jadi saya bantu dengan susu formula,, ”(Ny. Dn).

“... saya memang hanya susu formula saja, karena saya sakit. Dalam sehari anak saya minum 1 sampai 2 botol sehari, hari itu sampai 2. Terkadang juga sampai 3 botol ..."(Ny. Rt).

Dalam hal lamanya pemberian ASI, 3 dari 4 informan yang diwawancai mengetahui bahwa pemberian ASI kepada anak sebaiknya dilakukan hingga umur mereka mencapai dua tahun. Namun dalam praktiknya, hanya satu informan yang tetap memberikan ASI hingga dua tahun. Sedangkan dua informan lainnya memberikan ASI hanya sampai anak mereka mencapai umur 5 dan 11 bulan. Berikut kutipan wawancaranya:

“... saya pernah dengar kalau anak itu bagusnya diberi ASI sampai usia 2 tahun. Tapi saya hanya memberikan ASI sampai usia 5 bulan, karena ASI saya sudah tidak keluar ..."(Ny. Nt).

“... Sampai saat ini saya masih memberikan ASI kepada anak saya, kadang saya selingi dengan susu formula. ...” (Ny. Dn).

Hal ini sesuai dengan pernyataan dari informan biasa yang merupakan keluarga dari informan kunci, Bahwa anak tidak diberi ASI sampai berusia 2 tahun Berikut kutipan wawancaranya :

“... ada tiga orang ibu balita yang stunting, memberikan ASI kepada anaknya hanya sampai umur 10 bulan lebih, setelah itu diberikan susu formula, karena air susunya sudah tidak bisa keluar ..."(Ny. At).

“... ada satu orang ibu balita yang stunting, sampai saat ini anaknya masih diberi ASI, namun dibantu dengan susu formula..'(Ny. Rn).

Berdasarkan hasil wawancara dengan keempat informan kunci diperoleh hasil bahwa 2 dari 4 informan memberikan makanan tambahan kepada anaknya saat usiannya kurang dari 6 bulan, sedangkan 2 informan kunci lainnya memberikan anak makan pendamping ASI ketika anaknya sudah berusia 6 bulan. Berikut kutipan wawancaranya :

“... usia 5 bulan saya sudah mulai memberikan makanan kepada anak saya ..."(Ny. Nt).

“... sejak usia 4 bulan anak saya sudah diberikan makanan ...”(Ny. Rt).

“... nanti usia 6 bulan anak saya diberikan makanan pendamping ..."(Ny. Nf).

Alasan ibu memberikan MP-ASI pada anak $<6$ bulan karena ia merasa bahwa apabila anak hanya diberi susu tidak cukup untuk kebutuhan gizi anak. Alasan informan lainnya memberikan MP-ASI $<6$ bulan karena anaknya rewel dan dianggap bawah anaknya lapar. Berikut kutipan wawancaranya : 
“... anak saya itu berat badannya $\mathrm{ku}$ rang makanya saya kasih makanan supaya berat badannya naik, karena susu saja tidak cukup ..."(Ny. Rt).

“... anak saya itu suka rewel makanya saya coba kasih makan, ternayata setelah dikasih makan anak saya tidak rewel lagi, jadi mungkin dia itu rewel karena lapar ..."(Ny. Nt).

Dari hasil wawancara juga diperoleh bahwa makanan yang pertama kali diberikan kepada anak berbeda-beda. Ada ibu yang memberikan makanan lumat (bubur saring dan pisang yang dikerik). Namun ada juga ibu yang memberikan bubur bayi instan kepada anak. Berikut kutipan wawancaranya:

“... Pertama kali anak saya makan pisang yang di kerik, dia saya beri makan dua kali sehari, pagi dan malam ..."(Ny. Nt).

“... makanan yang saya berikan waktu pertama diberikan itu bubur yang disaring yang terbuat dari beras yang dicampur dengan bayam, dan saya beri makan dua kali sehari pagi dan sore, kadang kalau anak saya lagi malas makan dia biasa hanya makan 1 kali saja ..."(Ny. Nf).

“... Makanan yang pertama kali diberikan untuk anak saya yaitu SUN, saya kasih 2 kali sehari ..."(Ny. Dn).

Dari hasil wawancara terhadap informan kunci juga ditemukan bahwa semua balita yang mengalami stunting telah diberikan nasi ketika umur anaknya sekitar satu tahun. Selain nasi sebagai makanan pokok, anak juga lebih sering diberikan makanan dengan satu macam lauk dan sayur untuk setiap kali makan seperti telur yang dicampur dengan kecap. Terkadang juga diberi makan ikan, tahu atau tempe. Untuk jenis sayur yang diberikan adalah bayam, jagung, labu siam, kangkung. Dalam hal pemberian sayur, ada anak yang mau untuk makan sayur dan ada pula anak yang tidak mau makan sayur. Berikut kutipannya :

“... mendekati usia satu tahun saya beri makan nasi dengan campuran kuah ikan atau sayur agak lembek. Saat usia satu tahun ke atas, anak saya itu sudah mulai makan seperti makanan keluarga di rumah. Saya berikan dia (anak) nasi, kemudian lauknya kadang ikan goreng, kadang juga tempe/tahu, kalau untuk sayur saya berikan sayur bayam, kelor, atau kangkung, pokoknya tergantung jenis makanan yang tersedia di rumah. $\mathrm{Cu}$ man terkadang anak saya malas makan apalagi kalau dia sudah makan makan ringan." (Ny. Rt).

Hal ini sesuai dengan pernyataan yang informan biasa yang merupakan keluarga dari informan kunci yang tinggal serumah. Dapat dilihat pada kutipan wawancara sebagai berikut:

“... kalau saya lihat anaknya biasa dikasih nasi sama air sayur, kadang juga dikasih nasi sama ikan ..." (Ny. At).

“... kadang anaknya dikasih susu, kalau untuk makan dia biasanya kasih nasi, kemudian lauknya itu ikan goreng, kalau untuk sayur saya lihat anaknya itu jarang makan sayur, paling cuman nasi sama ikan atau tempe 
saja ..."(Ny. Dw).

Untuk pemberian buah pada anak balita, seluruh informan mengatakan hal yang serupa, di mana balita jarang diberi makan buah. Ibu memberikan buah jika teredia buah di rumah dan jenis buah yang diberikan rata-rata informan memberikan buah pisang. Berikut kutipan wawancaranya:

“... kalau dirumah lagi ada buah ya saya kasih buah, biasanya jeruk atau pisang, tapi yang paling sering pisang, soalnya mudah di dapat ..." (Ny. Nf).

Dari hasil wawancara diperoleh bahwa frekuaensi makan balita adalah 2-3 kali sehari. Berikut kutipannya wawancaranya :

“... Biasanya anak saya makan 3 kali dalam sehari, pagi, siang sama malam, ..."(Ny. Dn).

“... Dalam sehari dia makan cuman 2 kali pagi sama sore ...” (Ny. Nt).

Untuk jenis makanan pokok yang diberikan pada balita adalah nasi, dengan porsi dalam sekali makan antara 2 sampai 8 sendok makan ukuran sedang. Terdapat dua balita yang sulit untuk makan dan tidak dihabiskan. Sedangkan dua balita lainnya dapat menghabiskan makanan yang diberikan. Berikut kutipan wawancaranya:

“... anak saya itu makannya sedikit, paling tiap kali makan 4 sampai 5 suap saja satu kali makan. Tiap kali makan saya kasih nasi yang dicampur air sayur dan tempe atau tahu. ..." (Ny. Nt).
Hasil wawancara juga didapatkan bahwa ibu sering memberikan jajan kepada balitanya. Berikut kutipan wawancaranya:

“... anak saya paling sering jajan, karna kebetulan saya juga punya warung jadinya dia (balita) selalu jajan. Biasa dia makan biskut dan permen ..." (Ny. $\mathrm{Nf}$ ).

“... namanya anak-anak pasti suka jajan, biasanya dia kalau jajan paling snack, wafer dan es ..." (Ny. Nt).

Berdasarkan hasil wawancara dengan petugas gizi di Puskesmas Abeli didapatkan informasi bahwa pola pengasuhan ibu khususnya dalam mengolah dan memberikan makan masih kurang baik. Informasi tersebut dapat dilihat pada kutipan wawancara berikut:

“... Terutama untuk anak balita yang mengalami stunting yang kami pantau, rata-rata memang jadwal makannya tidak menentu. Ibunya juga sering memberikan jajan sama anaknya seperti snack, permen, es dll. Karena kalau tidak dikasih anaknya suka menangis, akhirnya ketika jam makan anaknya itu sudah malas makan karena sudah dikasih jajanan. Kemudian untuk porsi sekali makan rata-rata anak diberikan 3-8 sendok makan nasi dengan campuran lauk dan sayur, tetapi lebih sering si anak tidak menghabiskan porsi makanannya. Harusnya ibunya bisa lihat situasi si anak itu kalau porsi makannya kecil baiknya lebih sering diberi makan, artinya biar sedikit yang penting sering diberikan makan ..." (Ny. Ri). 


\section{PEMBAHASAN}

Menurut World Health Organization et al. (2020) bayi dengan berat badan lahir rendah adalah bayi yang lahir dengan berat di bawah 2500 gram. Berat tersebut diperoleh setelah ditimbang dalam waktu satu jam pertama setelah lahir. Dari hasil penelitian diperoleh bahwa tiga dari empat balita yang mengalami stunting ketika lahir mengalami berat badan lahir rendah (BBLR) atau <2500gr. Hal tersebut merupakan salah satu pencetus utama mengapa terjadinya stunting di kecamatan Abeli. Berdasarkan penelusuran data melalui wawancara terhadap ibu Balita, didapatkan informasi bahwa ibu jarang memeriksakan kehamilannya di fasilitas pelayanan kesehatan (bidan, posyandu, puskesmas dan dokter praktek) sehingga tidak ada pemantauan kesehatan selama proses kehamilan, bahkan ada ibu yang sama sekali tidak pernah memeriksakan kehamilannya. Rata-rata ibu berkunjung ke Posyandu saat kehamilan hanya 1-2 kali kunjungan saja.

Hasil wawancara diketahui bahwa, alasan ibu tidak rutin melakukan pemeriksaan kehamilan (antenatal care) beragam, ada yang mengatakan malas untuk ke posyandu, lupa jadwal posyandu dan ada juga ibu yang sibuk karena harus menjaga warung dan mengurus anaknya yang masih kecil.

Menurut Quinn et al. (2016) berat badan lahir rendah (BBLR) dibagi menjadi dua macam yaitu bayi lahir kecil dengan berat badan yang seharusnya untuk masa gestasi (dismatur) dan yang kedua bayi lahir kecil akibat kurang bulan. Menurut Woldeamanuel et al. (2019) faktor penyebab BBLR dapat dipengaruhi oleh status gizi ibu saat hamil. Selain itu usia ibu lebih dari 35 tahun atau kurang dari 20 tahun, terlalu dekatnya jarak kehamilan, paritas serta faktor dari janin juga dapat mempengaruhi kondisi berat bayi saat lahir (Fitri, 2018)

Hasil penelitian ini juga sejalan dengan penelitian yang dilakukan oleh Rahayu et al. (2015) yang mengemukakan bahwa berat lahir merupakan faktor dominan terjadinya stunting pada bayi berusia dua tahun. Sebesar 1.55 kali lipat bayi dengan berat badan lahir rendah akan memiliki risiko stunting dibandingkan dengan baduta yang tidak memiliki riwayat BBLR. Bayi dengan berat lahir rendah juga akan memberikan dampak status gizi dari generasi ke generasi selanjutnya. Berat lahir pada umumnya sangat berkaitan dengan perkembangan jangka panjang. Sehingga, pengaruh lanjutan dari berat kelahiran rendah ini dapat berupa gagal tumbuh (grouth faltering). Berat lahir merupakan prakiraan kuat terhadap penentuan ukuran tubuh di kemudian hari. Hal ini karena pada umumnya bayi yang mengalami Intra Uter- 
ine Growth Retardation (IUGR) tidak dapat mengejar pertumbuhan ke bentuk normal selama masa kanak-kanak.

Seseorang bayi yang lahir dengan BBLR akan sulit dalam mengejar ketertinggalan pertumbuhan awal. Pertumbuhan yang tertinggal dari yang normal akan menyebabkan anak tersebut menjadi stunting. Anak dengan riwayat berat lahir rendah akan memiliki ukuran antropometri yang kurang di masa dewasa (Lada et al., 2019).

Berdasarkan wawancara dengan bidan di Puskesmas Abeli diperoleh informasi bahwa dua dari empat orang ibu balita stunting mengalami KEK pada saat hamil di mana ukuran lingkar lengan atas (LILA) pada saat hamil kedua informan tersebut $<$ $23.5 \mathrm{~cm}$. Ibu hamil yang mengalami KEK dapat menjadi salah satu penyebab bayi lahir dengan BBLR.

Dibandingkan dengan ibu yang tidak mengalami KEK, ibu hamil yang mengalami KEK memiliki risiko melahirkan anak dengan BBLR dari pada. KEK dapat menjadi faktor tidak langsung kematian ibu. Pertumbuhan dan perkembangan janin dapat terganggu yang akan berdampak dengan kejadian BBLR. Hal ini dikarenakan ibu hamil yang mengalami kekurangan energi tidak memiliki simpanan zat gizi untuk menyuplai kebutuhan fisiologi kehamilan seperti volume darah untuk janin (Hartiningrum \& Fitriyah, 2019)
Hasil penelitian juga menunjukkan bahwa ibu yang mengalami KEK dan dengan balita stunting, ada yang berusia 17 tahun pada saat hamil. Usia ibu dibawah 20 tahun pada umumnya belum mampu memenuhi kebutuhan gizinya sendiri, dikhawatirkan pasokan gizi untuk janin akan kurang, jika pada usia tersebut ibu dalam keadaan hamil. (Trihardiani, 2011).

ASI air susu yang mengandung semua zat gizi yang diperlukan oleh bayi untuk kebutuhan pertumbuhan bayi dan dihasilkan oleh ibu setelah proses persalinan dan. ASI eksklusif adalah pemberian ASI selama 6 bulan tanpa tambahan cairan lain, seperti air teh, madu, jeruk, susu formula, dan air putih, serta tanpa tambahan makanan padat, seperti pisang, bubur nasi, biskuit, bubur susu, serta nasi tim, kecuali mineral, vitamin dan obat (Mufdillah, 2017).

Berdasarkan hasil penelitian diketahui bahwa semua ibu yang Balitanya mengalami stunting tidak memberikan ASI secara eksklusif kepada Balitanya. Rendahnya informasi yang diperoleh ibu mengenai pentingnya ASI ekslusif sehingga mempengaruhi pemahaman ibu mengenai pentingnnya pemberian ASI ekslusif yang pada akhirnya hal ini menjadi faktor penyebab ibu tidak memberikan ASI ekslusif pada Balita. Keterbatasan pengetahuan ibu akan berisiko tinggi pada kesehatan dan pertumbuhan anak, baik dalam kandungan 
maupun pada tahap perkembangan anak

Hasil penelitian didapatkan bahwa terdapat ibu Balita yang tidak memberikan ASI di awal kelahiran bayi, alasannya karena ASI baru keluar setelah satu minggu pasca persalinan, sehingga bayi harus diberikan susu formula. Selain itu alasan informan lainnya sehingga mereka tidak memberikan ASI eksklusif kepada bayinya karena produksi ASI yang kurang dan dengan alasan ingin menambah berat badan anak, olehnya itu ibu memberikan susu formula dan memberikan MP-ASI sebelum usia bayi enam bulan. Selain itu, terdapat satu ibu Balita yang sama sekali tidak pernah memberikan ASI kepada Balitanya, alasannya karena ibu tersebut memiliki penyakit infeksi (TBC) sehingga ibu takut akan dapat menulari anaknya, selain itu suami dan keluarganya juga melarang ibu Balita untuk memberikan ASI.

Hasil penelitian yang dilakukan di Banten didapatkan bahwa bayi stunting yang tidak diberikan ASI eksklusif selama 6 bulan mempunyai risiko 3,7 kali tetap stunting pada usia 3 - 4 tahun (Anugraheni \& Kartasurya, 2012).

Penelitian ini juga sejalan dengan penelitian yang dilakukan oleh Agustina \& Hamisah (2019), di mana balita yang tidak mendapat ASI eksklusif memiliki risiko yang sangat besar yaitu 35 kali terhadap kejadian stunting dibandingkan dengan
Balita yang mendapakan ASI eksklusif pada balita di wilayah kerja Puskesmas Reubee Kabupaten Pidie tahun 2019

The American Dietetic Association (ADA) dan The American Academy of Pediatric (AAP) merekomendasikan agar ASI eksklusif diberikan selama 6 bulan pertama kepada bayi kepada bayi selama 6 kemudian dilanjutkan dengan diberikan makanan pendamping ASI (MP-ASI) minimal hingga usia 12 bulan. Pengaruh ASI eksklusif terhadap stunting disebabkan oleh fungsi ASI sebagai anti infeksi, olehnya itu jika pemberian ASI yang kurang dan pemberian makanan atau formula terlalu dini dapat meningkatkan risiko stunting karena bayi cenderung lebih mudah terkena penyakit infeksi seperti diare dan penyakit pernafasan (Anugraheni \& Kartasurya, 2012).

Untuk memberikan dukungan pengurangan kasus stunting, diperlukan kerja sama yang melibatkan semua stakeholder. Selain itu pemberian pelayanan kesehatan neonatal kepada ibu hamil secara intensif dan mendorong ibu untuk memberikan air susu ibu (ASI) secara eksklusif. Keterlibatan semua unsur masyarakat secara kolektif juga diperlukan guna meningkatkan gizi anak Indonesia

Makanan pendamping ASI (MP-ASI) merupakan proses transisi dari asupan yang semata berbasis susu menuju ke makanan yang semi padat. Pengenalan dan pem- 
berian MP-ASI harus dilakukan secara bertahap baik bentuk maupun jumlahnya, sesuai dengan kemampuan pencernaan bayi/ anak. ASI hanya memenuhi kebutuhan gizi bayi sebanyak $60 \%$ pada bayi usia $6-12$ bulan. Sisanya harus dipenuhi dengan makanan lain yang cukup jumlahnya dan baik gizinya. Oleh sebab itu pada usia 6 bulan ke atas bayi membutuhkan tambahan gizi lain yang berasal dari MP-ASI (Mufida et al., 2015).

Dalam penelitian ini, terkait pemberian MP-ASI diketahui bahwa terdapat oleh ibu balita yang memberikan MP-ASI pada saat usia anak $<6$ bulan. Sedangkan dua informan lainnya memberikan MP-ASI ketika usia anak $>6$ bulan. Berdasarkan hasil wawancara dengan ibu balita, penyebab pemberian MP-ASI yang dini atau kurang dari 6 bulan karena ibu beranggapan bahwa anak membutuhkan makanan agar berat badan anak bertambah. Sedangkan informan lainnya menyatakan alasan memberikan MP-ASI kurang dari 6 bulan agar anak tidak rewel.

Berdasarkan hasil penelitian bahwa, jenis makanan yang pertama diberikan kepada Balita adalah bubur saring dan pisang kerik. Terkadang ibu juga menambahkan dengan sayuran namun lebih sering hanya diberikan bubur polos saja. Selain itu, ada juga ibu yang memberikan makanan/ bubur kemasan siap saji sebagai MP-ASI.

Pola pemberian MP-ASI pada balita masih kurang baik di mana frekuensi makan rata-rata diberikan 2-3 kali sehari, namun terkadang anak hanya makan 1-2 kali sehari karena anak lebih sering diberi makanan jajanan. Adapun porsi makan yang diberikan adalah 3 sampai 8 sendok makan namun lebih sering Balita tidak menghabiskan makanannya. Berdasarkan hasil wawancara, didapatkan bahwa penyebab dari kurang baiknya pengelolaan makan Balita disebabkan karena rendahnya pemahaman ibu terkait MP-ASI yang tepat untuk anak.

Dari hasil wawancara juga didapatkan informasi bahwa pengaturan pola makan Balita masih kurang baik, di mana jadwal makan Balita yang terkadang tidak teratur, selain itu makanan yang diberikan kepada balita tidak bervariasi, di mana terkadang ibu hanya memberikan nasi dan kuah ikan/ sayur saja atau hanya memberi makan nasi dan telur saja. Menu makanan yang tidak bervariasi akan mempengaruhi nafsu makan anak yang akhirnya dapat menimbulkan anak malas makan. Selain itu kebiasaan ibu yang sering memberikan Balitanya makanan jajanan juga menyebabkan berkurangnya nafsu makan anak Balita.

Jenis makanan yang tidak beragam akan menyebabkan tidak optimalnya asupan zat gizi pada balita. Usia 6 bulan sampai 1 tahun merupakan periode emas pertum- 
buhan dan perkembangan bayi secara motorik dan kognitif. Hal ini sangat bergantung pada kuantitas dan kualitas asupan ASI dan MP-ASI yang diberikan kepada bayi. Pada masa ini, pemenuhan kebutuhan gizi bayi perlu diperhatikan karena berdampak pada pencapaian tumbuh kembang yang optimal pada masa selanjutnya. Selain itu, pada masa ini juga bayi sangat rentan mengalami kekurangan zat gizi dan berisiko mengalami gagal tumbuh dan stunting di masa depan (Loya \& Nuryanto, 2017).

Penelitian ini sejalan dengan penelitian yang dilakukan oleh Meilyasari \& Isnawati (2014) di mana usia makan pertama balita usia 12 bulan merupakan faktor penentu kejadian stunting di desa Purwokerto Kecamatan Patebon, Kabupaten Kendal. Selain itu, penelitian di India memaparkan bahwa pemberian MP-ASI terlalu dini dapat meningkatkan risiko penyakit infeksi seperti penyakit diare karena MP-ASI yang diberikan tidak mudah dicerna seperti ASI. Hal tersebut dapat meningkatkan risiko terjadinya stunting pada usia 2-4 tahun dikarenakan pemberian MP-ASI pada usia dini yaitu di usia 0 sampai 2 bulan (Prihutama et al., 2018). Diare dapat mengakibatkan terjadinya kegagalan tumbuh anak karena terjadi malabsorpsi zat gizi selama diare (Caron et al., 2018).

\section{KESIMPULAN}

Berat Badan Lahir Rendah (BBLR) merupakan penyebab kejadian stunting pada anak balita di Kecamatan Abeli. Dari keempat balita yang mengalami stunting tiga di antaranya mengalami BBLR. Pemberian ASI eksklusif merupakan penyebab terjadinya stunting di Kecamatan Abeli. Penelitian ini menemukan bahwa masih banyak anak yang tidak mendapatkan ASI Ekslusif sampai usia 6 bulan. Selain itu, MP -ASI yang diberikan kurang bervariasi, porsi yang tidak cukup, dan frekuensi pemberian yang tidak teratur.

\section{SARAN}

Pihak puskesmas khususnya bagian poli gizi, sebaiknya secara rutin melakukan sosialisasi, diskusi atau cara lainnya untuk meningkatkan pengetahuan masyarakat terkait stunting dan apa penyebabnya, manfaat ASI eksklusif, serta bagaimana pemberian MP-ASI yang tepat untuk balita. Diperlukan peran serta keluarga, kader posyandu dan petugas kesehatan dalam memberikan dukungan sejak ibu hamil, termasuk dalam proses mengasuh anak. Diperlukan peran aktif ibu untuk rutin memeriksakan kehamilannya di fasilitas pelayanan kesehatan. Selain itu ibu harus dapat memberikan ASI eksklusif dan dilanjutkan sampai usia 2 tahun kepada anaknya. Ibu balita perlu meningkatkan pengetahuan terkait 
mengolah makanan yang sehat dan beraneka ragam, agar dapat memberikan asupan nutrisi yang cukup bagi anaknya.

\section{DAFTAR PUSTAKA}

Abdurahman, A. A., Mirzaei, K., Dorosty, A. R., Rahimiforoushani, A., \& Kedir, H. (2016). Household food insecurity may predict underweightand wasting among children aged 24-59 months. Ecology of food and nutrition, 55(5), 456-472. https:// doi.org/10.1080/03670244.2016.12070 69

Abubakar, A., Holding, P., Mwangome, M., \& Maitland, K. (2011). Maternal perceptions of factors contributing to severe under-nutrition among children in a rural African setting. Rural and remote health, 11(1), 1423. https:// pubmed.ncbi.nlm.nih.gov/21323398/

Agustina, A., \& Hamisah, I. (2019). Hubungan Pemberian Asi Ekslusif, Berat Bayi Lahir Dan Pola Asuh Dengan Kejadian Stunting Di Wilayah Kerja Puskesmas Reubee Kabupaten Pidie. Journal Of Healthcare Technology And Medicine, 5(2), 162-170. https:// doi.org/10.33143/jhtm.v5i2.397

Akombi, B. J., Agho, K. E., Hall, J. J., Merom, D., Astell-Burt, T., \& Renzaho, A. M. (2017). Stunting and severe stunting among children under-5 years in Nigeria: A multilevel analysis. $B M C$ pediatrics, 17(1), 15. https://doi.org/10.1186/ s12887-016-0770-z

Altmann, M., Altare, C., Van Der Spek, N., Barbiche, J. C., Dodos, J., Bechir, M., Aissa, M. A., \& Kolsteren, P. (2018). Effectiveness of a household water, sanitation and hygiene package on an outpatient program for severe acute malnutrition: a pragmatic cluster- randomized controlled trial in Chad. The American journal of tropical medicine and hygiene, 98(4), 10051012. https://doi.org/10.4269/ajtmh.170699

Ampaabeng, S. K., \& Tan, C. M. (2013). The long-term cognitive consequences of early childhood malnutrition: the case of famine in Ghana. Journal of health economics, 32(6), 1013-1027. https://doi.org/10.1016/j.jhealeco.2013. 08.001

Anugraheni, H., \& Kartasurya, M. (2012). Faktor risiko kejadian stunting pada anak usia 12-36 bulan di Kecamatan Pati, Kabupaten Pati. Journal of Nutrition College, 1(1), 3037. https://doi.org/10.14710/jnc.v1i1.72 5

Beal, T., Tumilowicz, A., Sutrisna, A., Izwardy, D., \& Neufeld, L. M. (2018). A review of child stunting determinants in Indonesia. Maternal \& child nutrition, $\quad 14(4), \quad$ e12617. https://doi.org/10.1111/mcn.12617

Black, R. E., Victora, C. G., Walker, S. P., Bhutta, Z. A., Christian, P., de Onis, M., Ezzati, M., Grantham-McGregor, S., Katz, J., Martorell, R., Uauy, R., \& Maternal and Child Nutrition Study Group (2013). Maternal and child undernutrition and overweight in lowincome and middle-income countries. Lancet (London, England), 382(9890), 427-451. https://doi.org/10.1016/S01406736(13)60937-X

Caron, Y., Hong, R., Gauthier, L., Laillou, A., Wieringa, F. T., Berger, J., \& Poirot, E. (2018). Stunting, beyond acute diarrhoea: Giardia duodenalis, in Cambodia. Nutrients, 10(10), 1420. https://doi.org/10.3390/nu10101420 
Coghlan, C. M., \& Bhagwat, S. A. (2019). Going beyond hunger: Linking food supplies to global malnutrition. Norsk Geografisk Tidsskrift-Norwegian Journal of Geography, 73(2), 128-134. https://doi.org/10.1080/00291951.2019. 1569125

De Silva, I., \& Sumarto, S. (2018). Child malnutrition in Indonesia: can education, sanitation and healthcare augment the role of income?. Journal of International Development, 30(5), 837-864. https://doi.org/10.1002/jid.3365

Desyanti, C., \& Nindya, T. S. (2017). Hubungan riwayat penyakit diare dan praktik higiene dengan kejadian stunting pada balita usia 24-59 bulan di wilayah kerja Puskesmas Simolawang, Surabaya. Amerta Nutrition, 1(3), 243-251. http://dx.doi.org/10.20473/amnt.v1i3.2 017.243-251

Dinas Kesehatan Kota Kendari. (2019). Profil Kesehatan Kota Kendari Tahun 2018. Kendari: Dinas Kesehatan Kota Kendari.

Dinas Kesehatan Provinsi Sulawesi Tenggara. (2019). Profil Kesehatan Provinsi Sulawesi Tenggara Tahun 2018. Kendari: Dinas Kesehatan Provinsi Sulawesi Tenggara

Donini, L. M., Poggiogalle, E., Pinto, A., Giusti, A. M., \& del Balzo, V. (2015). Malnutrition in the Elderly. In Diet and Nutrition in Dementia and Cognitive Decline (pp. 211-222). Academic Press. https://doi.org/10.1016/B978-012-407824-6.00020-3

Fitri, L. (2018). Hubungan BBLR Dan Asi Ekslusif Dengan Kejadian Stunting Di Puskesmas Lima Puluh Pekanbaru. Jurnal Endurance, 3(1), 131-137. http://doi.org/10.22216/jen.v3i1.1767
Goudet, S., Griffiths, P., Bogin, B., \& Madise, N. (2017). Interventions to tackle malnutrition and its risk factors in children living in slums: a scoping review. Annals of Human Biology, 44(1), $1-10$.

https://doi.org/10.1080/03014460.2016. 1205660

Hartiningrum, I., Nurul Fitriyah, N. (2018). Bayi berat lahir rendah (BBLR) di Provinsi Jawa Timur tahun 2012-2016, Jurnal Biometrika dan Kependudukan, $7(2)$, 97-104. http://dx.doi.org/10.20473/jbk.v7i2.201 8.97-104

Huang, C., Phillips, M. R., Zhang, Y., Zhang, J., Shi, Q., Song, Z., ... \& Martorell, R. (2013). Malnutrition in early life and adult mental health: evidence from a natural experiment. Social science \& medicine, 97, 259-266. https://doi.org/10.1016/j.socscimed.201 2.09.051

Husseini, M., Darboe, M. K., Moore, S. E., Nabwera, H. M., \& Prentice, A. M. (2018). Thresholds of socio-economic and environmental conditions necessary to escape from childhood malnutrition: a natural experiment in rural Gambia. BMC medicine, 16(1), 199. https://doi.org/10.1186/s12916-0181179-3

Kien, V. D., Lee, H. Y., Nam, Y. S., Oh, J., Giang, K. B., \& Minh, H. V. (2016). Trends in socioeconomic inequalities in child malnutrition in Vietnam: findings from the Multiple Indicator Cluster Surveys, 2000-2011. Global health action, $\quad 9(1), \quad 29263$. https://doi.org/10.3402/GHA.V9.29263

Kinyoki, D. K., Manda, S. O., Moloney, G. M., Odundo, E. O., Berkley, J. A., Noor, A. M., \& Kandala, N. B. (2017). Modelling the ecological comorbidity of acute respiratory infection, diarrhoea 
and stunting among children under the age of 5 years in Somalia. International Statistical Review, 85(1), 164-176. https://doi.org/10.1111/insr.12206

Lada, C. O., Batubara, J. R., Bardosono, S., Irawati, A., \& Salimar, S. (2019). Comparing The Anthropometric Measurements of Intra-Extra Uterine Period between Stunting and Non-stunting Children Aged 6-24 Months Old in Bogor Tengah Subdistrict, Bogor City, West Java. World Nutrition Journal, 3(1), 1-7. https://doi.org/10.25220/WNJ.V03.i1.0 002

Loya, R., \& Nuryanto, N. (2017). Pola asuh pemberian makan pada bayi stunting usia 6-12 bulan di Kabupaten Sumba Tengah, Nusa Tenggara Timur. Journal of Nutrition College, 6(1), 8495. https://doi.org/10.14710/jnc.v6i1.16 897

Mahmudiono, T., Nindya, T. S., Andrias, D. R., Megatsari, H., \& Rosenkranz, R. R. (2016). The effectiveness of nutrition education for overweight/obese mothers with stunted children (NEO-MOM) in reducing the double burden of malnutrition in Indonesia: study protocol for a randomized controlled trial. $B M C$ public health, 16(1), 486. https://doi.org/10.1186/s12889-0163155-1

Meilyasari, F., \& Isnawati, M. (2014). Faktor risiko kejadian stunting pada balita usia 12 bulan di Desa Purwokerto Kecamatan Patebon, Kabupaten Kendal. Journal of Nutrition College, $3(2)$, 303309. https://doi.org/10.14710/jnc.v3i2.5 437

Mufdlilah, M. (2017). Buku pedoman pemberdayaan ibu menyusui pada program ASI eksklusif [Universitas Aisyiyah Yogyakarta]. http://digilib.unisayogya.ac.id/4083

Mufida, L., Widyaningsih, T. D., \& Maligan, J. M. (2015). Prinsip Dasar Makanan Pendamping Air Susu Ibu (MPASI) Untuk Bayi 6-24 Bulan: Kajian Pustaka [In Press September 2015]. Jurnal Pangan dan Agroindustri, 3(4). 1646-1651. https://jpa.ub.ac.id/index.php/jpa/article /view/290/

Myatt, M., Khara, T., Dolan, C., Garenne, M., \& Briend, A. (2019). Improving screening for malnourished children at high risk of death: a study of children aged 6-59 months in rural Senegal. Public health nutrition, 22(5), 862871..

https://doi.org/10.1017/S13689800180 0318X

Oktiva, B. R., \& Adriani, M. (2017). Perbedaan Kadar Zinc Rambut pada Anak Stunting dan Non Stunting Usia 12-24 Bulan di Kelurahan Tambak Wedi Kenjeran, Surabaya. Amerta Nutrition, $\quad 1(2), \quad 133-142$. http://dx.doi.org/10.20473/amnt.v1i2.2 017.133-142

Prihutama, N. Y., Rahmadi, F. A., \& Hardaningsih, G. (2018). Pemberian Makanan Pendamping ASI Dini Sebagai Faktor Risiko Kejadian Stunting pada Anak Usia 2-3 Tahun. Jurnal Kedokteran Diponegoro, 7(2), 14191430.

https://ejournal3.undip.ac.id/index.php/ medico/article/view/21288

Quinn JA, Munoz FM, Gonik B, et al. Preterm birth: Case definition \& guidelines for data collection, analysis, and presentation of immunisation safety data. Vaccine. 2016;34(49):6047-6056. https://doi.org/10.1016/j.vaccine.2016. 03.045

Rahayu, A., Yulidasari, F., Putri, A. O., \& 
Rahman, F. (2015). Riwayat berat badan lahir dengan kejadian stunting pada anak usia bawah dua tahun. Kesmas: National Public Health Journal, 10(2), 67-73.

http://dx.doi.org/10.21109/kesmas.v10i 2.882

Rasheed, S., \& Woods, R. T. (2013). Malnutrition and quality of life in older people: a systematic review and metaanalysis. Ageing research reviews, 12(2), 561-566. https://doi.org/10.1016/j.physbeh.2014. 02.051

Rohmah, S., Suyatno, S., \& Kartasurya, M. (2018). Berat badan lahir rendah sebagai faktor risiko dominan terhadap kejadian gagal tumbuh pada anak usia 6-24 bulan. Jurnal Kesehatan Masyarakat (e-Journal), 6(5), 445 453.

https://ejournal3.undip.ac.id/index.php/ jkm/article/view/22069

Trihardiani, I. (2011). Faktor risiko kejadian berat badan lahir rendah di wilayah kerja Puskesmas Singkawang Timur dan Utara Kota Singkawang [Doctoral dissertation, Diponegoro University]. http://eprints.undip.ac.id/32555/

Woldeamanuel, G. G., Geta, T. G., Mohammed, T. P., Shuba, M. B., \& Bafa, T. A. (2019). Effect of nutritional status of pregnant women on birth weight of newborns at Butajira Referral Hospital, Butajira, Ethiopia. SAGE open medicine, 7 , 1-7. https://doi.org/10.1177/2050312119827 096

World Health Organization (2013). Essential Nutrition Actions: Improving Maternal, Newborn, Infant and Young Child Health and Nutrition. https://www.who.int/nutrition/publicati ons/infantfeeding/essential_nutrition_a ctions/en/

World Health Organization, UNICEF, \& The World Bank Group Joint Child Malnutrition Estimates. (2020). Levels And Trends In Child Malnutrition. https://www.who.int/publications/i/ite $\mathrm{m} / \mathrm{jme}$-2020-edition 